\title{
Growth of tyrosine kinase inhibitor-resistant Philadelphia-positive acute lymphoblastic leukemia: Role of bone marrow stromal cells
}

\author{
CHENG ZHANG, XI ZHANG, SHI-JIE YANG and XING-HUA CHEN \\ Department of Hematology, Xinqiao Hospital, Third Military Medical University, Chongqing 400037, P.R. China
}

Received July 14, 2015; Accepted November 4, 2016

DOI: $10.3892 / \mathrm{ol} .2017 .5686$

\begin{abstract}
Human bone marrow stromal cells (hBMSCs) may contribute to the growth of tyrosine kinase inhibitor (TKI)-resistant chronic myelogenous leukemia (CML). However, there are certain differences in biology between CML and Philadelphia-positive acute lymphoblastic leukemia $\left(\mathrm{Ph}^{+} \mathrm{ALL}\right)$. Little is known about the role and mechanism of hBMSCs on the growth of TKI-resistant $\mathrm{Ph}^{+} \mathrm{ALL}$. The current study co-cultured hBMSCs with the TKI-resistant SUP-B15. Next, the proliferation of SUP-B15 was detected using a Cell Counting Kit-8. Additionally, quantitative polymerase chain reaction and flow cytometry were used to detect the expression of the associated genes and proteins. The present study explores the role and mechanism of hBMSCs on the growth of TKI-resistant $\mathrm{Ph}^{+}$ALL. The current study showed that hBMSCs promoted the proliferation of TKI-resistant $\mathrm{Ph}^{+} \mathrm{ALL}$. This was shown by the increase in cells in the $\mathrm{S}+\mathrm{G} 2-\mathrm{M}$ phase of the cell cycle. It was also found that the expression of cyclins A, C, D1 and $\mathrm{E}$ was increased. Apoptosis was inhibited through upregulation of anti-apoptotic genes [B-cell lymphoma-2 (BCL-2) and BCL-extra large] and downregulation of apoptotic genes (BCL-XS, BCL-2-associated X protein, and caspases 3, 7 and 9). Expression of the breakpoint cluster region (BCR)-Abelson murine leukemia viral oncogene homolog 1 (ABL) gene, Wnt5a, and Wnt signaling pathway-associated genes (glycogen synthase kinase-3 $\beta$, $\beta$-catenin, E-cadherin and phosphoinositide 3-kinase) and transcription factors (c-myc, ephrin type-B2, fibroblast growth factor 20 and matrix metalloproteinase 7) was also increased. Furthermore, the expression of drug resistance genes (low-density lipoprotein receptor, multidrug resistance-associated protein and multi-drug resistance gene) was increased and the expression of anti-oncogenes (death-associated protein kinase and interferon regulatory factor-1) was decreased. It was concluded that hBMSCs promote the growth of TKI-resistant
\end{abstract}

Correspondence to: $\mathrm{Dr}$ Xing-Hua Chen, Department of Hematology, Xinqiao Hospital, Third Military Medical University, 183 Xinqiao Street, Chongqing 400037, P.R. China

E-mail: xhchen888@aliyun.com

Key words: growth, tyrosine kinase inhibitors, resistant, Philadelphia-positive acute lymphoblastic leukemia, mechanism, bone marrow stromal cells
$\mathrm{Ph}^{+}$ALL by these aforementioned mechanisms. Therefore, targeting hBMSCs may be a promising approach for preventing the growth of TKI-resistant $\mathrm{Ph}^{+}$ALL.

\section{Introduction}

In total, 25-30\% of adults and 3\% of children with Philadelphia-positive acute lymphoblastic leukemia $\left(\mathrm{Ph}^{+} \mathrm{ALL}\right)$ have a high rate of complete remission, but also have an extremely poor prognosis due to a high rate of relapse (1). The use of tyrosine kinase inhibitors (TKIs), combined with chemotherapy or subsequent to allogeneic hematopoietic stem cell transplant, improves the outcome of patients with $\mathrm{Ph}^{+} \mathrm{ALL}$. However, resistance to TKI is a vital aspect of $\mathrm{Ph}^{+} \mathrm{ALL}$ due to the emergence of breakpoint cluster region (BCR)-Abelson murine leukemia viral oncogene homolog 1 (ABL) mutations (2-5). Previous studies have suggested that upon TKI treatment pressure, chronic myelogenous leukemia (CML) stem cells survive due to BCR-ABL kinase-independent mechanisms (6-9).

It is well-known that stromal cells protect CML cells from TKI-induced cell death and mediate the resistance of CML to TKIs (10-15). Human bone marrow stromal cells (hBMSCs) regulate hematopoietic stem cell self-renewal, proliferation and differentiation, which play key roles in the relapse of leukemia (16-18). Targeting hBMSCs may therefore be a promising approach for TKI resistance and the prevention of relapse for $\mathrm{Ph}^{+} \mathrm{ALL}$, as the leukemia cells of CML are normally dependent on BCR-ABL signaling for growth and survival; solely inhibiting the BCR-ABL tyrosine kinase in $\mathrm{Ph}^{+} \mathrm{ALL}$ is not sufficient to inhibit leukemia cell growth $(19,20)$. Therefore, it is vital to understand the role and mechanism of hBMSCs on the growth of TKI-resistant $\mathrm{Ph}^{+}$ALL. However, there are few studies on the role and mechanism of hBMSCs on the growth of TKI-resistant $\mathrm{Ph}^{+}$ ALL.

\section{Materials and methods}

hBMSC culture. hBMSCs were isolated from 20 bone marrow samples obtained between December 2012 and December 2014 and cultured as described by our previous study (21). Bone marrow samples were obtained from newly diagnosed, untreated ALL patients, without infection, aged 18-30 years old. The samples were collected at Xinqiao Hospital, subsequent to obtaining written informed consent from the patients. 
Ethical approval was provided by the Ethics Committee of Xinqiao Hospital (Chongqing, China).

Culturing TKI-resistant SUP-B15 cells. The SUP-B15 human $\mathrm{Ph}^{+}$ALL cell line was purchased from the American Type Culture Collection (Manassas, VA, USA). The culture of TKI-resistant SUP-B15 cells (R+SUP-B15) was performed according to our previous study and the literature (20-24). Briefly, when logarithmic growth was observed in the SUP-B15 cells, the culture medium, Iscove's Modified Dulbecco's Medium (IMDM; Gibco; Thermo Fisher Scientific, Inc., Waltham, MA, USA) with 10\% FBS (Gibco; Thermo Fisher Scientific, Inc.) was changed to medium containing $2 \mu \mathrm{mol}-1$ Gleevec (Novartis, Basel, Switzerland). The majority of SUP-B15 cells died, and only a small number of SUP-B15 cells survived. For $\sim 3$ weeks, the surviving SUP-B15 cells were left to proliferate, and then the associated drug-resistant index [half maximal inhibitory concentration and multi-drug resistance gene (MDR1) level by reverse transcription-quantitative polymerase chain reaction (RT-qPCR)] and BCR-ABL (by RT-qPCR) were detected. These SUP-B15 cells were maintained for the following assays.

Coculture of hBMSCs with SUP-B15 cells. When the passaged hBMSCs reached $\sim 60 \%$ confluence, SUP-B15 cells and $\mathrm{R}+\mathrm{SUP}-\mathrm{B} 15$ cells were inoculated for coculture with hBMSCs with 5:1 with IMDM with $10 \% \mathrm{FBS}$ at $37^{\circ} \mathrm{C}$ with $5 \% \mathrm{CO}_{2}$. Subsequent to $1,4,7$ and 14 days (d1, d4, d7 and d14, respectively) of coculture, SUP-B15 cells and R+SUP-B15 cells were washed twice with PBS prior to subsequent analyses.

Drug sensitivity. The R+SUP-B15 cells were collected and were continuously cultured with hBMSCs with IMDM medium supplemented with $10 \%$ FBS and containing $250 \mathrm{ng}-\mathrm{ml}$ cyclophosphamide (Cy; Jiangsu Hengrui Medicine Co., Ltd., Lianyungang, China) for 1, 4, 7 and 14 days. The surviving cells were washed twice with PBS prior to subsequent analyses.

Clone forming test. A 2-layer soft agar culture system was used for this assay. A total of $1 \times 10^{3}$ cocultured R+SUP-B15 cells per $\mathrm{ml}$ were plated in a volume of $4 \mathrm{ml}$ IMDM (0.7\% agar) over $3-\mathrm{ml}$ base layers (1.2\% agar) in $60-\mathrm{mm}$ Petri dishes. The cultures were incubated in humidified $37^{\circ} \mathrm{C}$ incubators with an atmosphere of $5 \% \mathrm{CO}_{2}$, and control plates were monitored for growth using an inverted microscope on $\mathrm{d} 1, \mathrm{~d} 4, \mathrm{~d} 7$ and d14. Colony counts were obtained using an inverted microscope from at least 5 fields of view at a magnification of x100. Objects presenting a circular profile in 2 dimensions with a minimum diameter of $60 \mu \mathrm{m}$ were considered to be colonies.

Cell Counting Kit-8(CCK-8) assay. The coculturedR+SUP-B15

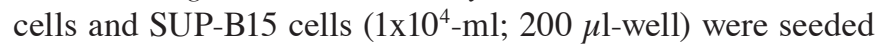
into 96-well plates as aforementioned and cultured for $4 \mathrm{~h}$. The single culture R+SUP-B15 cells $\left(1 \times 10^{4}-\mathrm{ml} ; 200 \mu 1\right.$-well) were plated as a control group. The proliferation was assessed according to our previous study using CCK-8 (Dojindo Molecular Technologies, Inc., Kumamoto, Japan) (25).

Cell cycle distribution. The R+SUP-B15 cells cultured with hBMSCs and R+SUP-B15 cells cultured with hBMSCs combined with Cy were collected and stained with propidium iodide (Sigma-Aldrich; Merck Millipore, Darmstadt, Germany). The nuclei were analyzed using flow cytometry (FACSCalibur; Beckon Dickinson, Franklin Lakes, NJ, USA). The percentage of cells at each phase of the cell cycle was estimated from the DNA-content histograms.

Flow cytometry for cyclins. The cocultured R+SUP-B15 cells were collected and stained for cyclins A (catalog no., C4710), D1 (catalog no., C7464), E (catalog no., SAB4503514) and C (catalog no., SAB4504700) (Sigma-Aldrich; Merck Millipore) at $4^{\circ} \mathrm{C}$ overnight. The cells were washed with 0.01 mol-1 PBS and stained with fluorescein isothiocyanate-anti-IgG (Sigma-Aldrich; Merck Millipore) at $37^{\circ} \mathrm{C}$ for $2 \mathrm{~h}$. The positive staining was detected using flow cytometry (FACSCalibur; Beckon Dickinson).

Flow cytometry for apoptosis. The cocultured cells and cocultured cells combined with Cy were collected. An Annexin V binding and propidium iodide uptake assay (R\&D Systems, Minneapolis, MN, USA) was employed for apoptosis analysis, as previously described (26).

Tumor forming test. Male NOD-SCID mice $(\mathrm{n}=20)$ were obtained from the Institute of Zoology, Chinese Academy of Sciences (Beijing, China). All mice were bred and maintained under specific pathogen-free conditions at $25^{\circ} \mathrm{C}$ in a $12 \mathrm{~h}$ light-dark cycle, with $50 \%$ humidity, in the Animal Center of the Third Military Medical University (Chongqing, China). The Ethical Review Committee of the Third Military Medical University (Chongqing, China) approved the experimental protocol. The SUP-B15 cells and R+SUP-B15 cells cultured with hBMSCs for 1, 4, 7 and 14 days were washed twice with serum-free RPMI-1640 medium. These cells were resuspended at a density of $1 \times 10^{7}$ cells-ml in serum-free RPMI-1640 medium. The mice were anesthetized with ether, and the cells were inoculated subcutaneously into SCID mice by a dorsal injection at a dose of $5 \times 10^{6}$ cells per mouse. Mice with tumors $1.5-2.0 \mathrm{~cm}$ in diameter were sacrificed during the 2-3-week follow-up period subsequent to inoculation with different coculture cells. The subcutaneous tumor was excised from the mice. The length, width and height of the tumor were measured using the Somers scale (27). Tumor tissues were sliced at 4- $\mu \mathrm{m}$ thickness, and Harris hematoxylin and eosin staining (American MasterTech, Lodi, CA, USA) was performed.

$R T$-qPCR. Subsequent to $1,4,7$, and 14 days of coculture, R+SUP-B15 cells were collected. Total RNA was extracted from the cells using TRIzol reagent and was then reverse-transcribed into cDNA. The mRNA expression of cyclins A, D1, E and C, caspases 3, 7, 8 and 9, the BCR-ABL gene, Wnt signaling pathway-associated genes [c-myc, matrix metalloproteinase 7 (MMP7), ephrin type-B2 (EphB2) and fibroblast growth factor 20 (FGF20)], anti-apoptotic genes [B cell lymphoma (Bcl)-2 and Bcl-extra large (XL)], apoptotic genes [Bcl-short isoform (xs) and Bcl-associated $\mathrm{X}$ protein (Bax)], anti-oncogenes [interferon regulatory factor (IRF-1) and death-associated protein kinase (DAPK)] and drug resistance genes [low-density lipoprotein receptor (LRP), 
Table I. Primers for reverse transcription-quantitative polymerase chain reaction.

\begin{tabular}{|c|c|c|}
\hline Gene & Sense, $5^{\prime}-3^{\prime}$ & Antisense, 5'-3' \\
\hline Cyclin A & TGTCACCGTTCCTCCTTG & GCATCTTCACGCTCTATTT \\
\hline Cyclin D1 & AGGAACAGAAGTGCGAGGAG & AGGCGGTAGTAGGACAGGAAG \\
\hline Cyclin C & TGATTGCTGCTGCTACTT & CCATTTGGACCCTGCTCT \\
\hline Cyclin E & CTGGATGTTGACTGCCTTGA & CCGCTGCTCTGCTTCTTAC \\
\hline c-myc & GGGCTTTATCTAACTCGCTGTA & TATGGGCAAAGTTTCGTG \\
\hline MMP7 & TATGGGACATTCCTCTGA & TCTGCCTGAAGTTTCTATT \\
\hline EphB2 & AGGACGATACCTCAGACCC & AGGACATCACCTCCCACAT \\
\hline FGF20 & CATCTTTAGGGAGCAGTTT & TGGAGTTCCGTCTTTGTTA \\
\hline $\mathrm{BCR} / \mathrm{ABL}$ & CTACGAGGACGCCGAGTTGA & TGCGAGTTCTGCGAGGGA \\
\hline Bcl-2 & ATGGCAAATGACCAGCAGA & GCAGGATAGCAGCACAGGA \\
\hline Bcl-XL & GGAGGCAGGCGACGAGTTT & GGACGGAGGATGTGGTGGA \\
\hline Bcl-Xs & TGAGGGAGGCAGGCGACGAGTT & ATGGCGGCTGGACGGAGGAT \\
\hline Bax & TTTGCTTCAGGGTTTCATCCA & GAGACACTCGCTCAGCTTCTTG \\
\hline Caspase-3 & TTTGGTACTGTATTTCCCTC & GCAGTTAAGTCATCCGTGT \\
\hline Caspase-7 & AGAATGTGGGTATTGAGTGT & GAGGGCAGGATAGGTGAGA \\
\hline Caspase- 8 & GCTGGTGGCAATAAATAC & AGAAGGCATAAAGCAAGT \\
\hline Caspase-9 & CGAACTAACAGGCAAGCA & TCACCAAATCCTCCAGAAC \\
\hline IRF1 & CTGAGTCTACAGCGTGTCTTC & CTGGGATTGGTGTTATGC \\
\hline DAPK & TTCGGCTCAAATCCCAATA & CCATCTGACACCGTCTTACA \\
\hline MDR1 & AAGCCTACAGCCGTGTCC & тсСТсСТCTTGGGTTTGG \\
\hline MRP & CGCTGAGTTCCTGCGTAC & GTTCTGCGGTGCTGTTGT \\
\hline LRP & CTTCAAGAACGCAGTGGTG & CAGTAGAGTTTGCTTTCAGGGA \\
\hline$\beta$-actin & GTGGACATCCGCAAAGAC & AAAGGGTGTAACGCAACTAA \\
\hline
\end{tabular}

MMP7, matrix metalloproteinase 7; EphB2, ephrin type-B2; FGF20, fibroblast growth factor 20; BCR/ABL, breakpoint cluster region/Abelson murine leukemia viral oncogene homolog 1; Bcl-2, B cell lymphoma-2; Bcl-XL, Bcl-extra large; Bax, Bcl-associated X protein; DAPK, death-associated protein kinase; IRF-1, interferon regulatory factor-1; MDR1, multi-drug resistance gene; MRP, multidrug resistance-associated protein; LRP, low-density lipoprotein receptor.

multidrug resistance-associated protein (MRP) and MDR1] were analyzed by qPCR using $\beta$-actin as an internal standard. The fold change of target gene expression in the experimental group compared with the control group was calculated using $2^{-\Delta \Delta \mathrm{Cq}}$, according to a previous study (19). The primers used were shown in Table I. The amplification conditions were as follows: $95^{\circ} \mathrm{C}$ for $3 \mathrm{~min}$; 40 cycles of $95^{\circ} \mathrm{C}$ for $20 \mathrm{sec}, 56^{\circ} \mathrm{C}$ for $20 \mathrm{sec}$ and $72^{\circ} \mathrm{C}$ for $20 \mathrm{sec} ; 95^{\circ} \mathrm{C}$ for $15 \mathrm{sec} ; 60^{\circ} \mathrm{C}$ for $15 \mathrm{sec}$; $60-95^{\circ} \mathrm{C}$ for $20 \mathrm{~min}$; and $95^{\circ} \mathrm{C}$ for $15 \mathrm{sec}$.

Western blot analysis. Subsequent to 1, 4, 7, and 14 days of coculture, R+SUP-B15 cells were collected. The expression of cyclins A, D1, E and C, BCR-ABL, Wnt signaling pathway-associated proteins (c-myc, MMP7, EphB2 and FGF20), anti-apoptotic proteins (Bcl-2 and Bcl-XL), apoptotic proteins (Bcl-xs and Bax), caspases 3, 7, 8 and 9 and drug resistance proteins (MDR1, MRP and LRP) was analyzed by western blot analysis, according to the manufacturer's protocol. Briefly, R+SUP-B15 cells from different time points were washed and resuspended in ice-cold PBS at a concentration of $1 \times 10^{6}$ cells-ml and were incubated in ice-cold RIPA buffer (Beyotime Institute of Biotechnology, Haimen, China). The cell suspensions were centrifuged at $10,000 \times \mathrm{g}$ at $4{ }^{\circ} \mathrm{C}$ and the supernatant was collected after $20 \mathrm{~min}$. The Bradford assay
(Beyotime Institute of Biotechnology) was used to measure the supernatant protein content. A total of $50 \mathrm{mg}$ protein extracts were separated by SDS-PAGE with $10 \%$ polyacrylamide gels and were subsequently transferred onto nitrocellulose membranes after thawing and boiling the protein samples in Laemmli buffer (Sigma-Aldrich; Merck Millipore) for $5 \mathrm{~min}$. Subsequent to blocking the membranes with $5 \%$ non-fat milk, the membranes were incubated overnight at $4^{\circ} \mathrm{C}$ with antibodies against: Cyclin A (catalog no., ab87359; dilution, 1:1,000; Abcam, Cambridge, UK); cyclin D1 (catalog no., ab134175; dilution, 1:10,000; Abcam); cyclin E (catalog no., ab33911; dilution, 1:2,000; Abcam); cyclin C (catalog no., ab78868; dilution, 1:500; Abcam); BCR-ABL (catalog no., ab187831; dilution, 1:500; Abcam); c-myc (catalog no., BM0238; dilution, 1:400; Shanghai Qiancheng Biological Technology Co., Ltd., Shanghai, China); MMP7 (catalog no., ab38996; dilution, 1:1,000; Abcam); EphB2 (catalog no., ab5418, 1:500; Abcam); FGF20 (catalog no., ab139054, 1:500, Abcam); BCL-2 (catalog no., ab32124; dilution, 1:1,000; Abcam); BCL-XL (catalog no., 10455-R016-50; dilution, 1:5,000; Sino Biological, Inc., Beijing, China); BCL-XS (catalog no., 101579-T32-50; dilution, 1:5,000; Sino Biological, Inc.); Bax (catalog no., ab32503; dilution, 1:2,000; Abcam); caspase 3 (catalog no., ab90437; dilution, 1:1,000; Abcam); caspase 7 (catalog no., ab201959; 
dilution, 1:1,000; Abcam); caspase 8 (catalog no., ab32397; dilution, 1:1,000; Abcam); caspase 9 (catalog no., ab202068; dilution, 1:1,000; Abcam); MDR1 (catalog no., ab170904; dilution, 1:1,000; Abcam); MRP (catalog no., ab32574; dilution, 1:500; Abcam); LRP (catalog no., ab32574; dilution, 1:500; Abcam); and $\beta$-actin (catalog no., ab8226; dilution, 1:5,000; Abcam). The cells were then incubated with goat anti-rabbit IgG horseradish peroxidase (HRP)-conjugated (catalog no., ab6721; dilution, 1:5,000; Abcam) and goat anti-mouse IgG HRP-conjugated (catalog no., ab6789; dilution, 1:10,000; Abcam) secondary antibodies at room temperature for $1 \mathrm{~h}$ after washing the membranes. The membranes were then developed with enhanced chemiluminescence solution (Thermo Fisher Scientific, Inc.). $\beta$-actin was used as a control.

ELISA assay. The supernatant of cocultured cells was collected. The expression of Wnt5a was detected by ELISA kit from Yi Han Biological Technology Co., Ltd., (Shanghai, China) according to the manufacturer's protocol.

Laser confocal microscopy. R+SUP-B15 cells cocultured with hBMSCs were collected and washed twice with PBS. The cells were permeated with $0.1 \%$ Triton X-100 for $15 \mathrm{~min}$, then washed with PBS and neutralized with $4 \%$ bovine serum albumin (Roche Diagnostics, Basel, Switzerland) for $30 \mathrm{~min}$. Antibodies against E-cadherin (rabbit monoclonal antibody; catalog no., SAB5500022), $\beta$-catenin (mouse monoclonal antibody; catalog no., C4231), phosphoinositide 3-kinase (PI3K; rabbit monoclonal antibody; catalog no., SAB5500162) and glycogen synthase kinase (GSK)-3 $\beta$ (rat polyclonal antibody; catalog no., G7914) (Sigma-Aldrich; Merck Millipore) were added overnight at $4^{\circ} \mathrm{C}$, at a dilution of 1:200 and then the cells were washed with PBS and FITC-anti-IgG was added for $1 \mathrm{~h}$ at $37^{\circ} \mathrm{C}$. The cells were washed with PBS and images were captured.

Scanning electron microscopy. Single culture R+SUP-B15 cells and R+SUP-B15 cells cocultured with hBMSCs were collected. The cells were washed with 0.01 phosphate buffer saline (PBS) (catalog no., PBS1; Sigma-Aldrich; Merck Millipore) subsequent to centrifugation at $1000 \mathrm{x} g$ for $5 \mathrm{~min}$ for double times, then the cells were dried onto polylysine-coated glass slides at room temperature for $\sim 1 \mathrm{~h}$. Subsequent to being washed with $0.01 \mathrm{PBS}$, the slides was fixed with 5\% lutaric dialdehyde at $4^{\circ} \mathrm{C}$ for $1 \mathrm{~h}$, then washed twice with 0.01 PBS for $>30$ min each time. Sequential fixation was performed with $1 \%$ osmic acid at $4^{\circ} \mathrm{C}$ for $1 \mathrm{~h}$. Subsequent to washing, the slides were dehydrated in turn by ethanol (catalog no., PHR1373; Sigma-Aldrich; Merck Millipore) with the concentrations of $30,50,70,80,90$ and $100 \%$. Replacement with liquid $\mathrm{CO}_{2}$ was performed by critical point drying, and the $\mathrm{CO}_{2}$ was removed while in a supercritical state. The dry specimen was sputtercoated with gold palladium alloy (catalog no., GF48929967; Sigma-Aldrich; Merck Millipore). The morphology of the cells was then observed using a scanning electron microscope.

Statistical analysis. Statistical analysis was performed using the SPSS 13.0 software package (SPSS, Inc., Chicago, IL, USA). The Wilcoxon signed-rank test was used to determine differences between paired samples, and the Mann-Whitney
U test was used to determine differences between different groups. Tukey's test was used to control for multiple comparisons. $\mathrm{P}<0.05$ was considered to indicate a statistically significant difference. Average values were expressed as the mean \pm standard error of the mean.

\section{Results}

\section{Cell proliferation}

Proliferation of $R+S U P-B 15$ cells. All cells demonstrated an increase in proliferation as culture time increased, and the peak proliferation rate was reached on $\mathrm{d} 4$ for $\mathrm{R}+\mathrm{SUP}-\mathrm{B} 15$ cells. However, the peak proliferation rate was achieved on $\mathrm{d} 7$ for R+SUP-B15 cells cultured with hBMSCs. The proliferation of R+SUP-B15 cells cultured with hBMSCs was faster than $\mathrm{R}+$ SUP-B15 cells cultured alone on $\mathrm{d} 7$ and $\mathrm{d} 14$ ( $\mathrm{P}<0.05$; Fig. 1A).

Clone formation. The clones for R+SUP-B15 cells cultured with hBMSCs were observed on $\mathrm{d} 4$. However, the clones for SUP-B15 cells cultured with hBMSCs were observed on d7. All numbers of clones increased with increasing culture time. The number of clones was increased in the R+SUP-B15 cells compared with the SUP-B15 cells cultured with hBMSCs on d14 ( $\mathrm{P}=0.021$; Fig. 1B).

Cell cycle analysis and cyclin expression. The rate of $\mathrm{S}+\mathrm{G} 2-\mathrm{M}$ phase gradually increased with increasing culture time, and the difference was statistically significant between d1 and $\mathrm{d} 7(\mathrm{P}<0.05$; Fig. 1C). The expression of cyclins was also detected using flow cytometry. The results showed that the expression of cyclins A, C, D1 and E gradually increased with increasing culture time, and the difference was statistically significant between $\mathrm{d} 1$ and $\mathrm{d} 7$ ( $\mathrm{P}<0.05$; Fig. 1D). Western blot analysis revealed that cyclins A, C, D1 and E gradually increased with increasing culture time, and the difference was statistically significant on $\mathrm{d} 4(\mathrm{P}<0.05$; Fig. $1 \mathrm{E})$. The RNA expression of cyclins A, C, D1 and E also gradually increased with increasing culture time, and the difference was statistically significant on $\mathrm{d} 4$ for cyclin $\mathrm{A}$ and $\mathrm{E}$ and on $\mathrm{d} 7$ for cyclin $\mathrm{C}$ and D1 ( $\mathrm{P}<0.05$; Fig. 1F).

Tumor formation in NOD-SCID mice. The tumors were observed in the skin of nude mice. The largest tumor was observed from the cells cultured with hBMSCs for 14 days. There was no difference in the size and weight of the tumors between the cell types prior to $\mathrm{d} 7(\mathrm{P}>0.05)$. The size and weight was increased in SUP-B15 cells compared to R+SUP-B15 cells cultured for 14 days $(\mathrm{P}<0.05)$. Numerous tumor cells were observed in the tumor with Harris hematoxylin staining, and neovascularization was observed in the cells cultured for 14 days (Fig. 1G).

\section{Expression of BCR-ABL and Wntsignaling pathway-associated genes}

Wnt gene expression. The expression of Wnt5a gradually increased with increasing culture time. The expression was significantly higher in R+SUP-B15 cells compared with SUP-B15 cells on d4, d7 and d14 ( $\mathrm{P}<0.05)$ (Fig. 2A).

Expression of Wnt signaling pathway-associated proteins. Laser confocal microscopy was used to detect the expression of Wnt signaling pathway-associated proteins. The expression of PI3K, GSK-3 $\beta$, E-cadherin and $\beta$-catenin gradually increased with increasing culture time. 

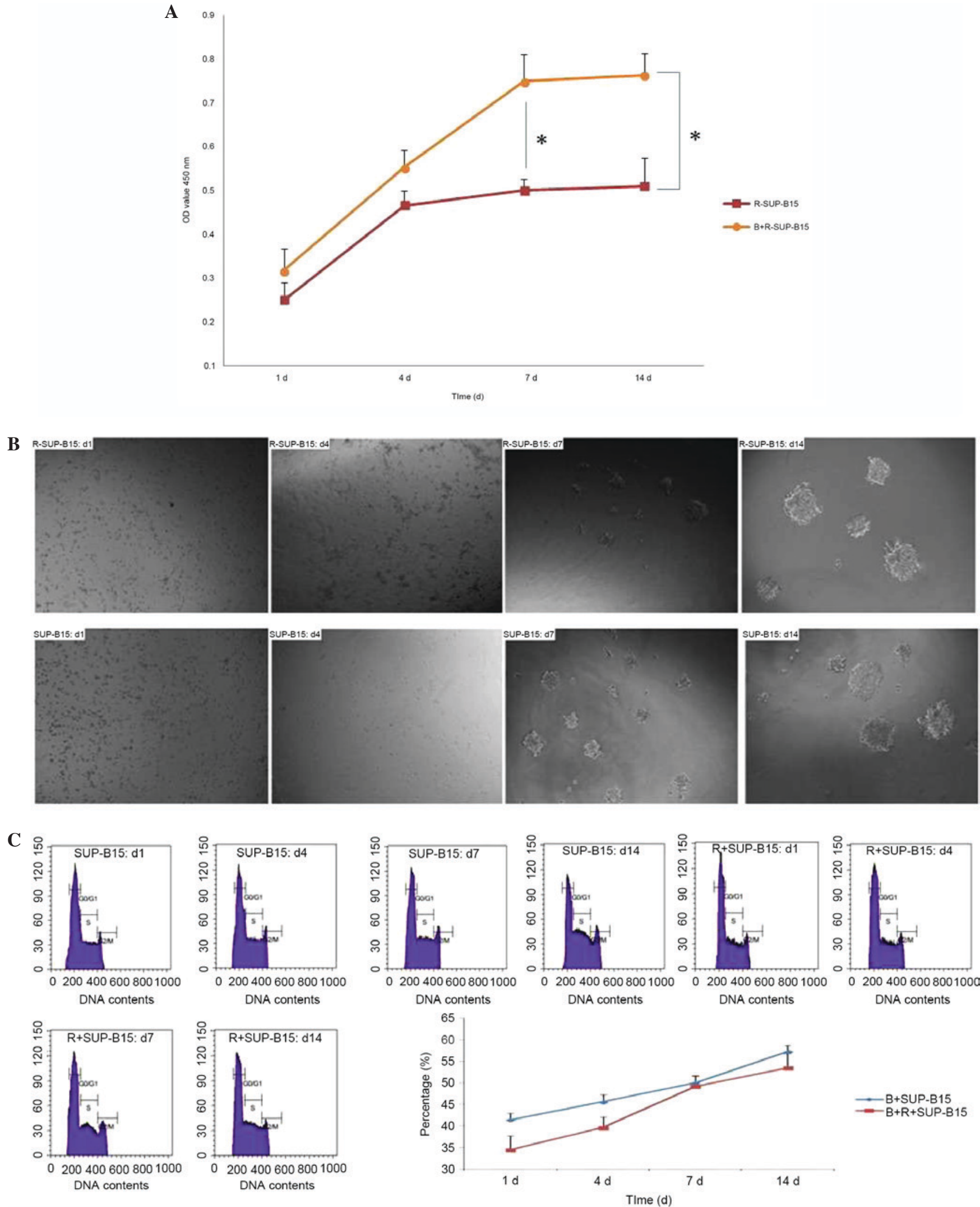

Figure 1. Proliferation of R+SUP-B15 cells cultured with hBMSCs. hBMSCs promoted the proliferation of R+SUP-B15 cells and gradually increased during culture. (A) Proliferation curves of the two cell lines. (B) Clone-forming assay (magnification, x100). (C) Cell cycle analysis. "P<0.05. R+SUP-B15, tyrosine kinase inhibitor-resistant SUP-B15 cells; OD, optical density; hBMSCs, human bone marrow stromal cells; d, days.

Green fluorescence protein was mainly located in the cell membranes and cytoplasm, and no change in location was observed (Fig. 2B).
Transcriptionfactors. hBMSCs promoted the protein expression of c-myc, EphB2, MMP7 and FGF20 and increased with increasing culture time, and the difference was statistically 
D
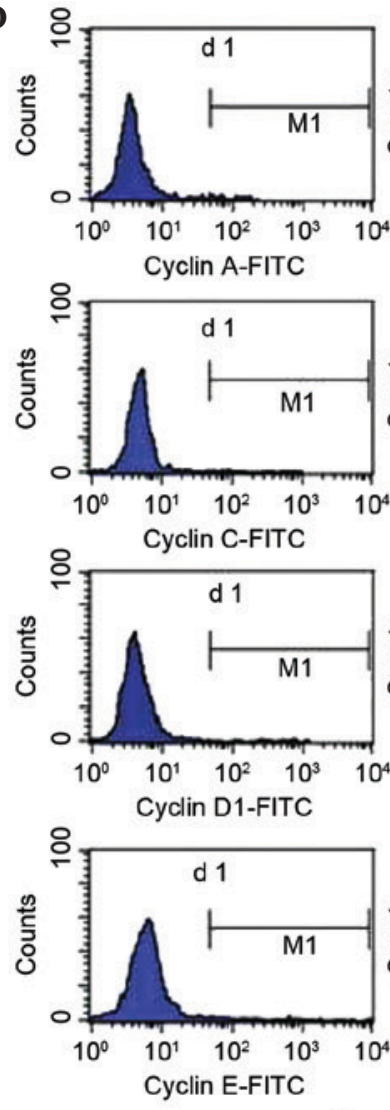
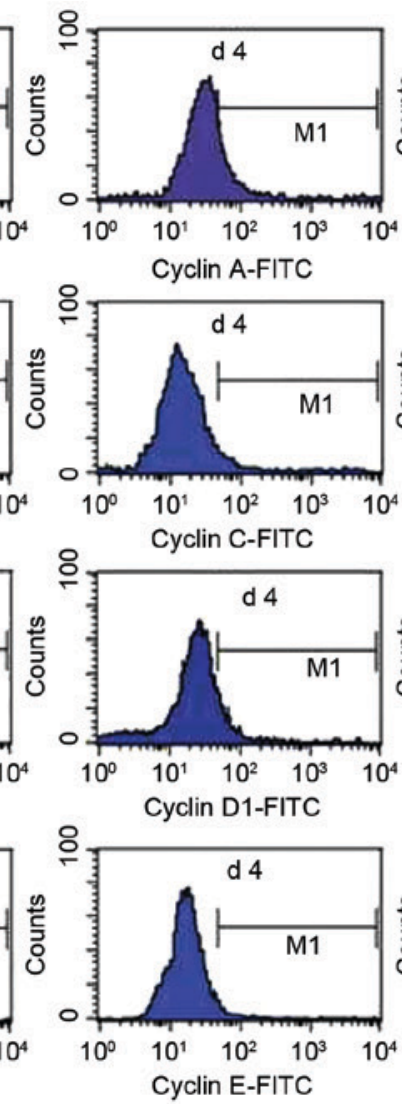

Cyclin E-FITC
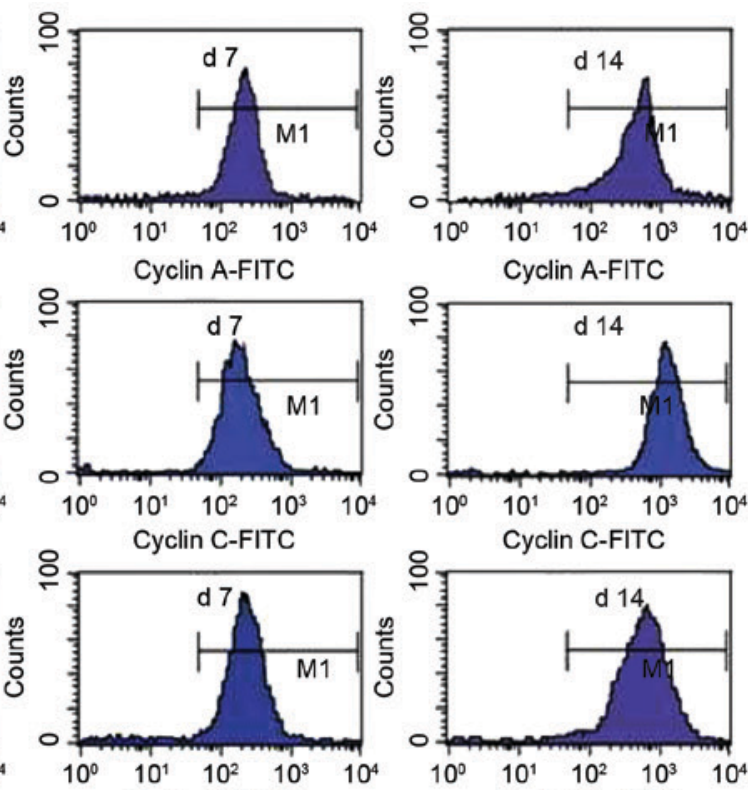

Cyclin D1-FITC
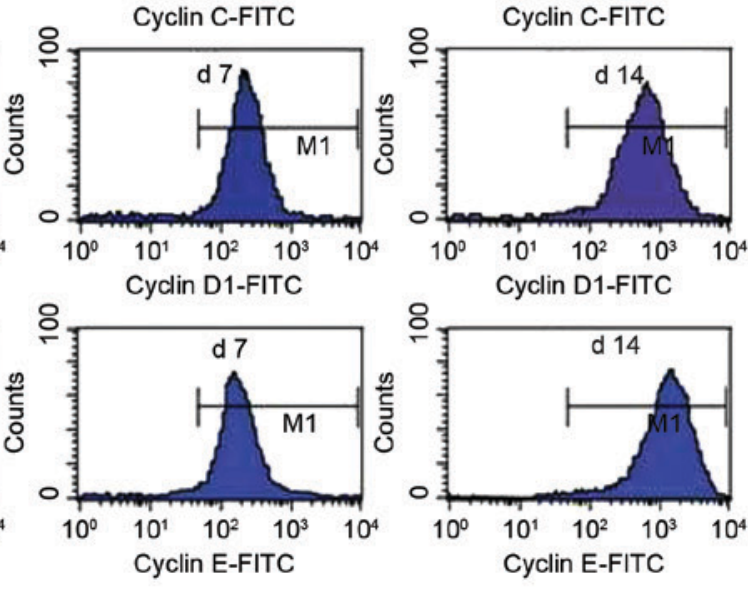

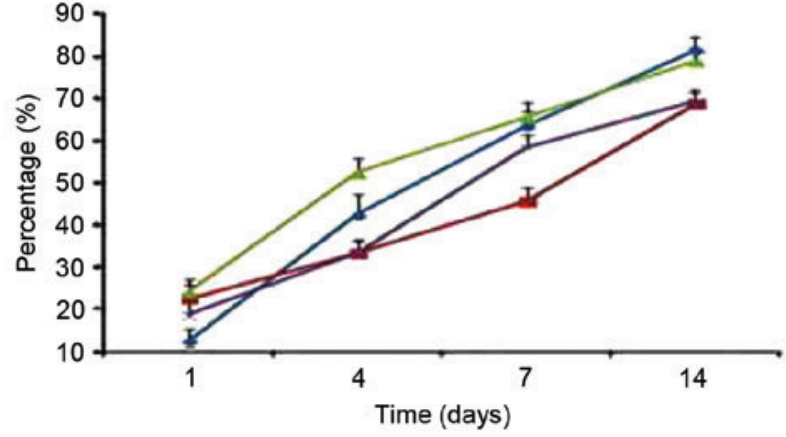

$\rightarrow$ Cyclin A

$\rightarrow-$ Cyclin C

- Cyclin D1

- Cyclin E

E
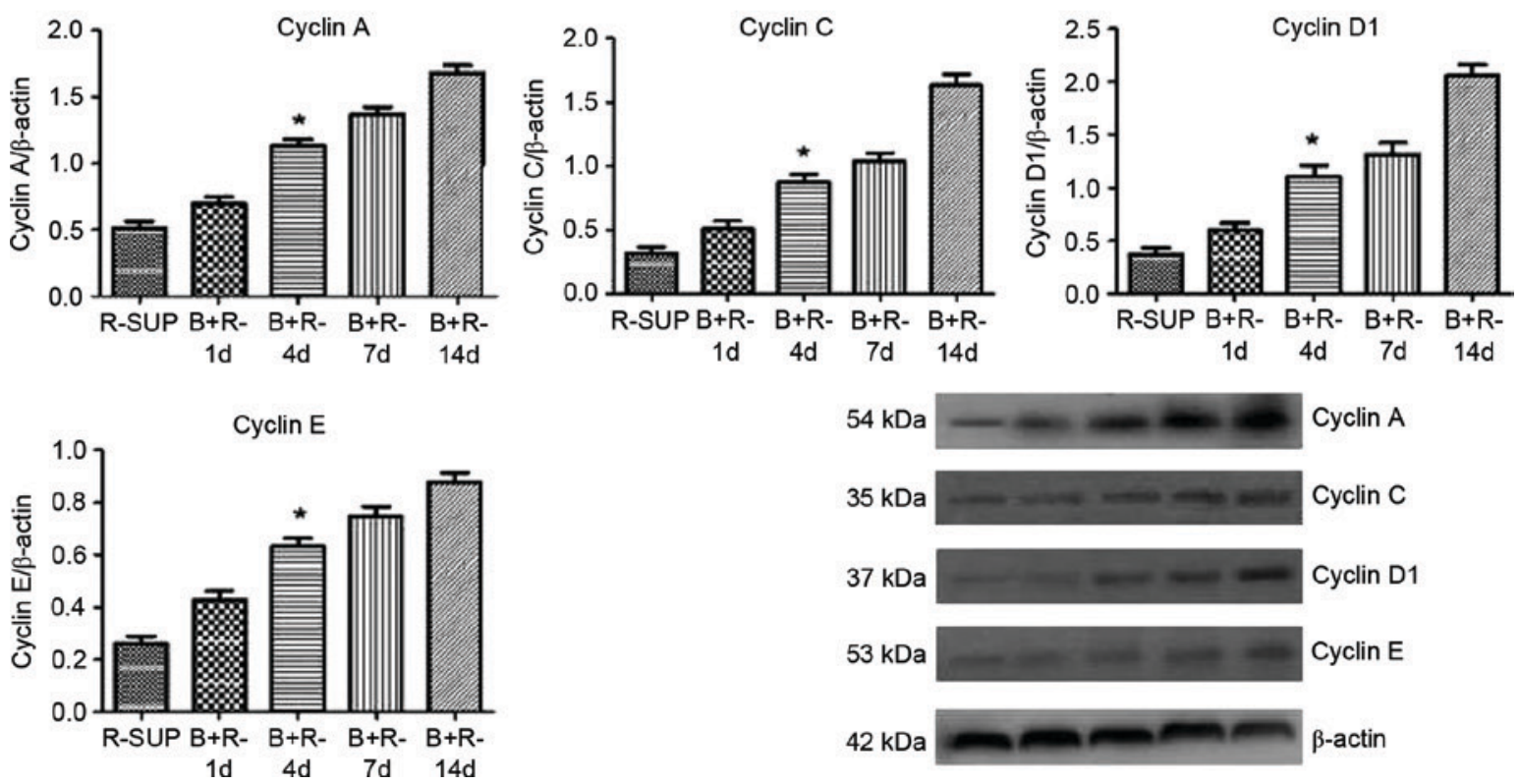

Figure 1. Continued. (D) Expression of cyclins detected by flow cytometry. (E) Expression of cyclin proteins detected by western blot analysis. $\mathrm{P}<0.05$. FITC, fluorescein isothiocyanate; d, days. 

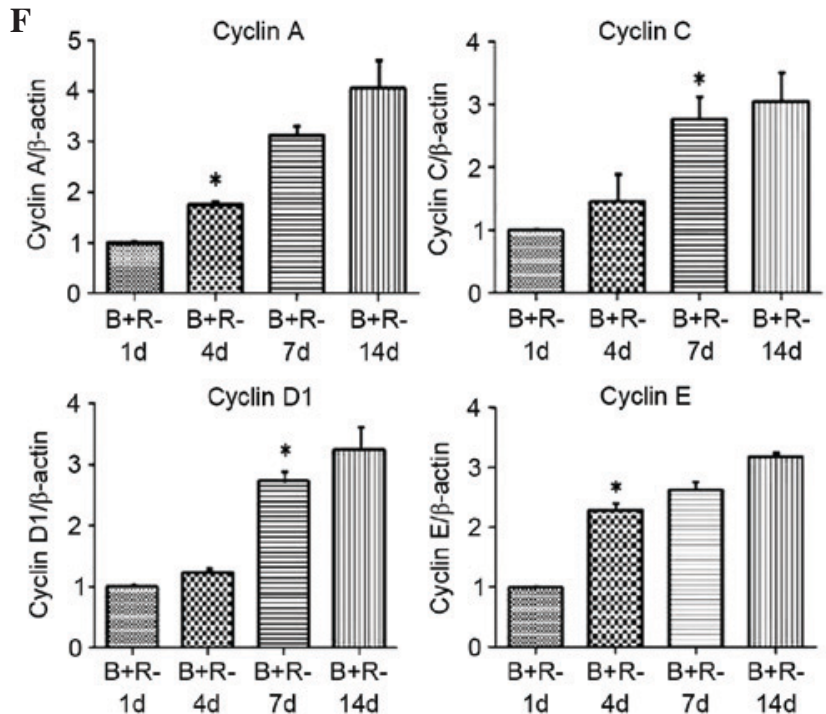

\section{G}
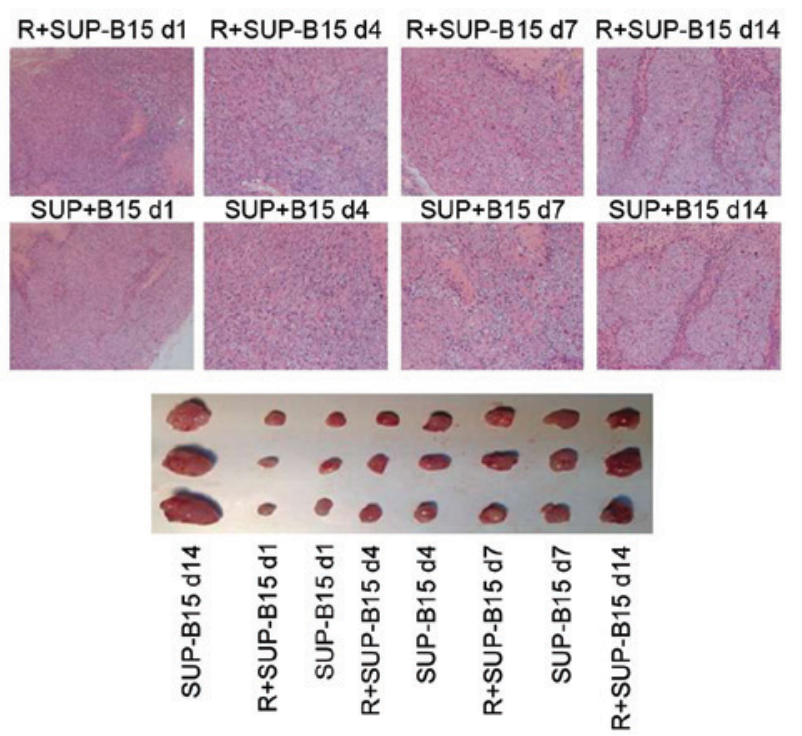

Figure 1. Continued. (F) Expression of cyclin mRNA detected by quantitative polymerase chain reaction. $(\mathrm{G})$ Tumor formation in nude mice ${ }^{*} \mathrm{P}<0.05$. R+SUP-B15 cells, tyrosine kinase inhibitor-resistant SUP-B15 cells; d, day.

significant on $\mathrm{d} 4$ compared with $\mathrm{d} 1$ ( $\mathrm{P}<0.05$; Fig. 2C). mRNA expression of c-myc, EphB2, MMP7 and FGF20 was detected by $\mathrm{qPCR}$, and the results showed that hBMSCs promoted the mRNA expression of c-myc, EphB2, MMP7 and FGF20 and increased with increasing culture time. The difference was statistically significant on d7 for EphB2 expression and on d14 for FGF20, c-myc and MMP7 expression (P<0.05; Fig. 2D).

$B C R-A B L$ gene. Western blotting showed that hBMSCs promoted the expression of BCR-ABL and gradually increased with increasing culture time, and the difference was statistically significant on $\mathrm{d} 4$ compared with $\mathrm{d} 1$ ( $\mathrm{P}<0.05$; Fig. $2 \mathrm{E})$. The mRNA expression of BCR-ABL detected with qPCR was also promoted by hBMSCs and gradually increased with increasing culture time, and the difference was statistically significant on d7 compared with d1 ( $\mathrm{P}<0.05$; Fig. 2F).

\section{Cell apoptosis}

Hoechst 33342-PI staining. Fluorescence staining with Hoechst 33342 gradually decreased with increasing culture time, and a significant decrease was observed on d14 compared with $\mathrm{d} 1$. However, no change was observed for the fluorescence staining with PI at any time point (data not shown).

Expression of anti-apoptotic and apoptosis-associated gene $m R N A$. mRNA expression of anti-apoptotic and apoptosis-associated genes was detected using qPCR, and the results showed that hBMSCs promoted the expression of anti-apoptotic genes (BCL-2 and BCL-XL) and decreased the expression of apoptotic genes (BCL-XS, Bax and caspases 3, 7 and 9) during the culture period. The difference was statistically significant on $\mathrm{d} 4$ for BCL-2, BCL-XL, Bax and caspase 9, and on $\mathrm{d} 7$ for BCL-XS, caspase 3 and caspase $7(\mathrm{P}<0.05)$. No change was observed for caspase 8 (Fig. 3B).

Expression of anti-apoptotic and apoptosis-associated proteins. The protein expression of anti-apoptotic and apoptosis-associated genes was further detected with western blot analysis, and the results showed that hBMSCs promoted the expression of anti-apoptotic proteins (BCL-2 and BCL-XL) and decreased the expression of apoptotic proteins (BCL-XS, Bax and caspases 3, 7 and 9) over the culture period. The difference was statistically significant on $\mathrm{d} 4$ compared with d1 $(\mathrm{P}<0.05)$. No change was observed for caspase 8 (Fig. 3C).

Morphological changes. The nucleus of R+SUP-B15 cells cultured with hBMSCs became smaller over time during the culture period while the cytoplasm, organelles, granucles and Golgi complexes became numerous, and the chromatin became slimmer. At the end of culture, the cells grew vigorously (Fig. 3D).

\section{Drug sensitivity}

Drug resistance genes. The expression of the drug resistance genes LRP, MRP and MDR1 was increased in R+SUP-B15 cells cultured with hBMSCs compared with R+SUP-B15 cells cultured alone and increased with increasing culture time. The difference between the two culture groups was statistically significant from d4 compared with d1 ( $\mathrm{P}<0.05$; Fig. 4A). qPCR was also used to detect mRNA expression. mRNA expression of LRP, MRP and MDR1 was increased in R+SUP-B15 cells cultured with hBMSCs compared with R+SUP-B15 cells cultured alone and increased with increasing culture time. The difference was statistically significant from $\mathrm{d} 4$ compared with d1 ( $\mathrm{P}<0.05$; Fig. 4B).

Anti-oncogene expression. The expression of DAPK and IRF-1 was increased in R+SUP-B15 cells cultured with hBMSCs compared with R+SUP-B15 cells cultured alone and decreased with increasing culture time, and the difference was statistically significant on $\mathrm{d} 4$ compared with $\mathrm{d} 1 \mathrm{(}<0.05$; Fig. 4C).

Cell cycle progression. The proportion of cells in the $\mathrm{S}+\mathrm{G} 2-\mathrm{M}$ phase gradually increased with increasing culture time in R+SUP-B15 cells cultured with hBMSCs combined with $\mathrm{Cy}$, and the difference was statistically significant from d7 compared with d1 $(\mathrm{P}<0.05$; Fig. 4D).

Cell apoptosis. No change was observed in the rate of apoptosis for R+SUP-B15 cells cultured with hBMSCs combined with Cy ( $>>0.05$; Fig. 4E).

\section{Discussion}

The tumor microenvironment not only plays a pivotal role during cancer progression and metastasis, but also has 
A

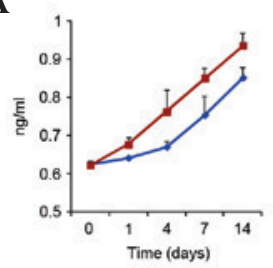

$\rightarrow$ B+R+SUP-B15
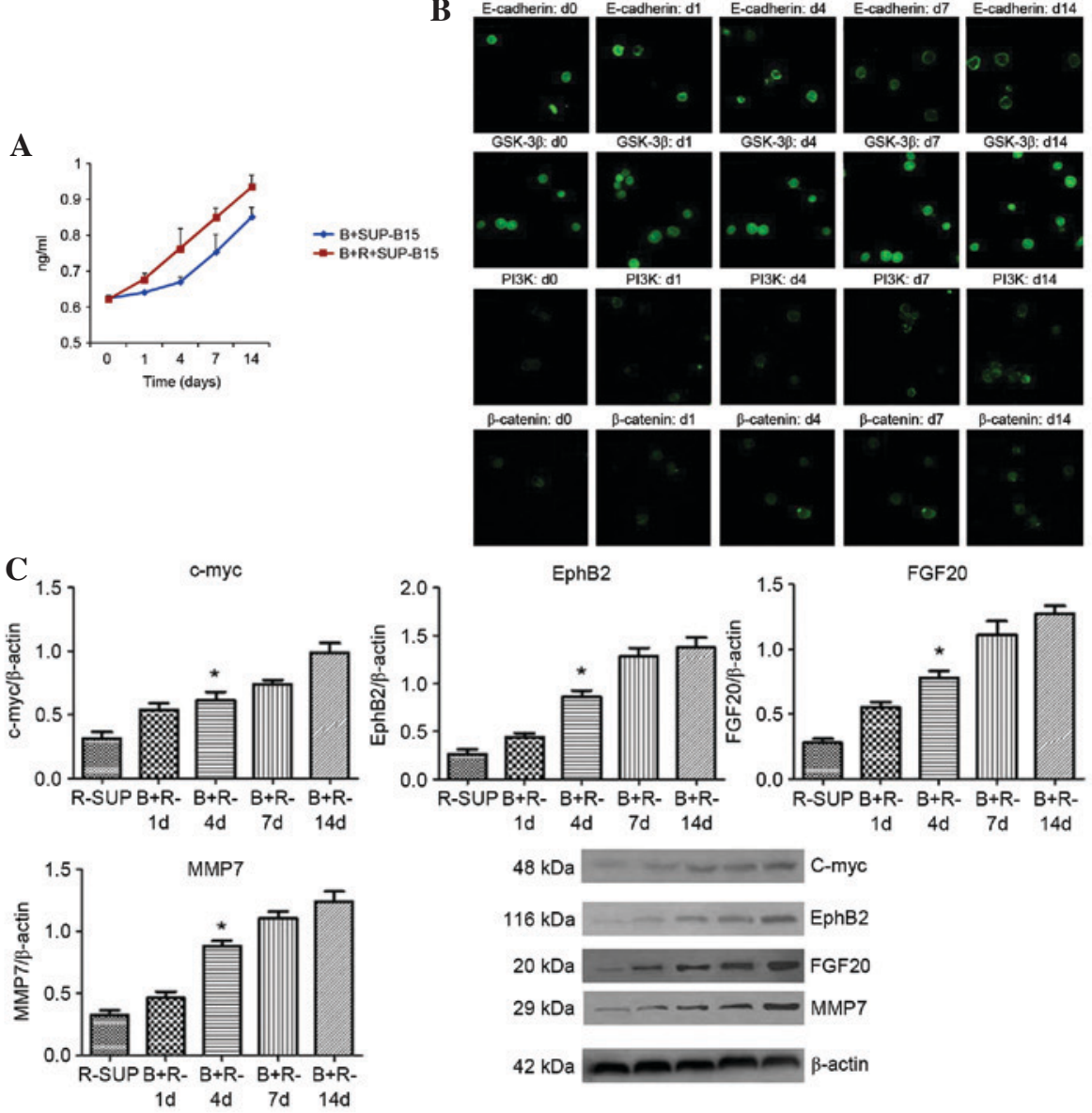

D
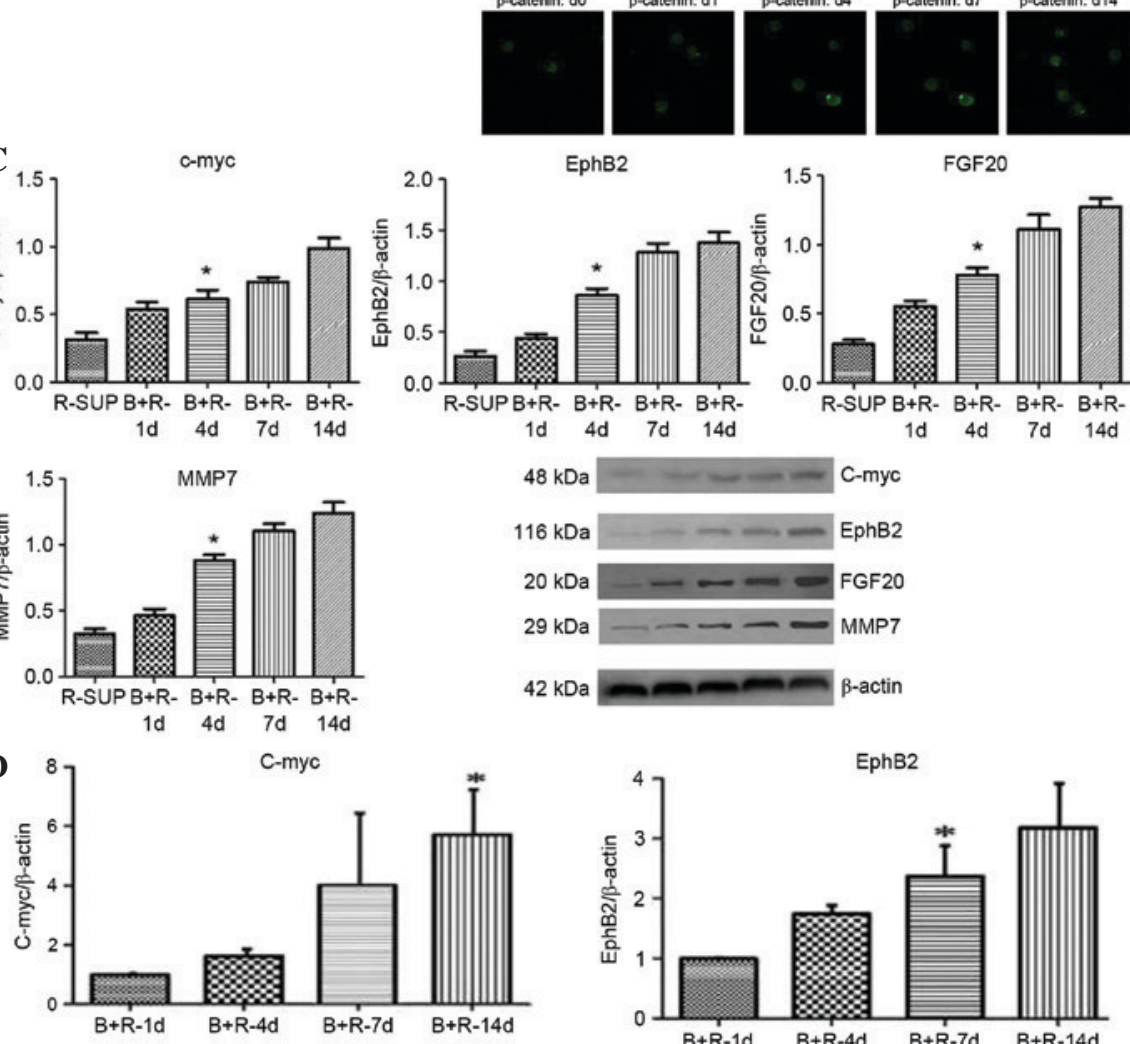

FGF20
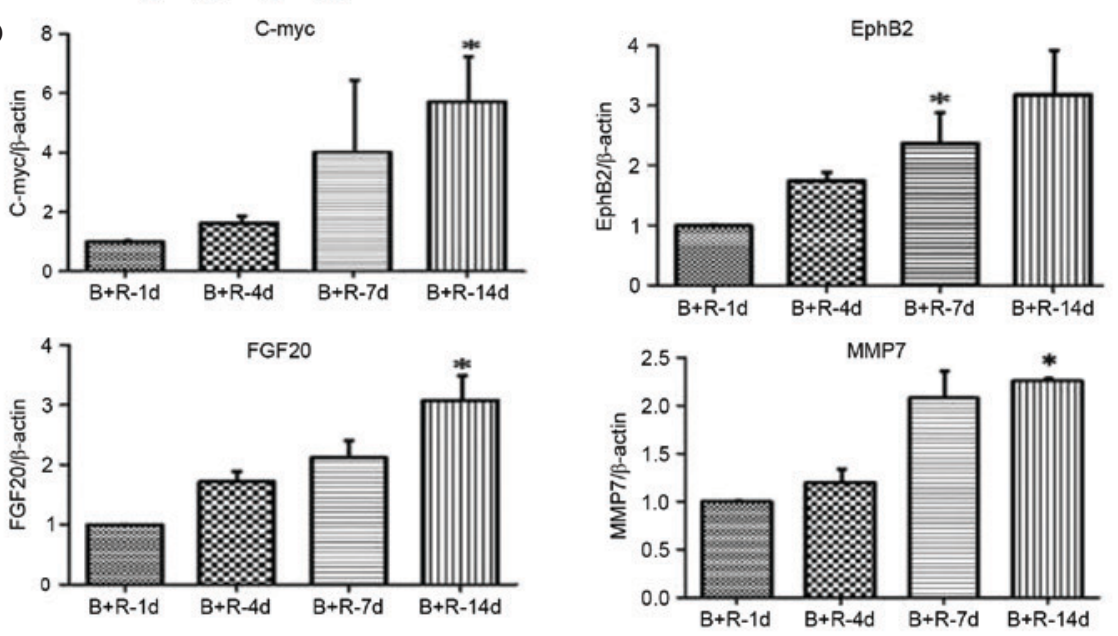

$\mathbf{E}$
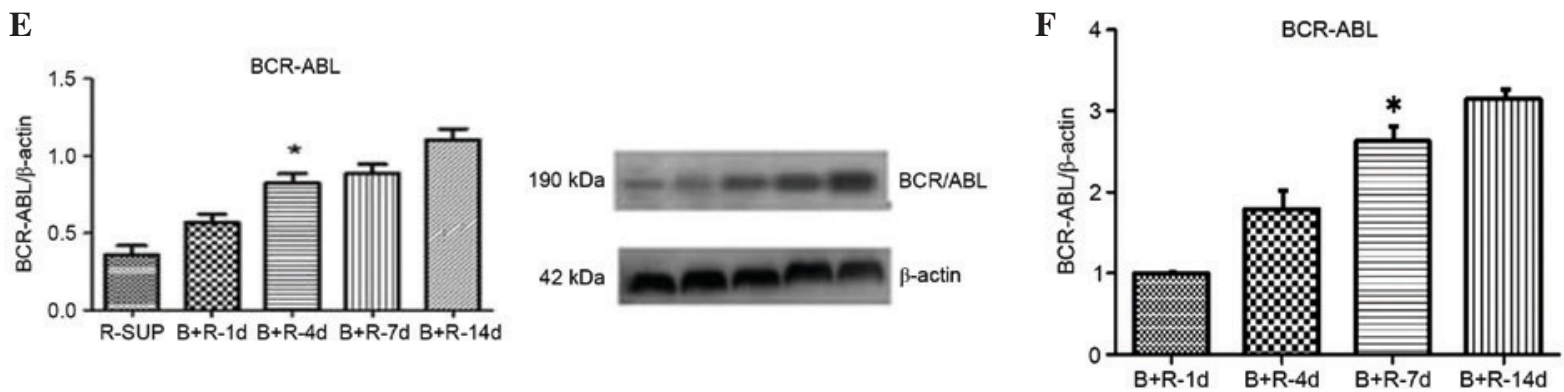

Figure 2. The expression of BCR/ABL and Wnt signaling pathway-associated genes and transcription factors in R+SUP-B15 cells cultured with hBMSCs. hBMSCs promoted the expression of BCR/ABL and Wnt signaling pathway-associated genes and transcription factors and gradually increased during culture. (A) Expression of Wnt. (B) Expression of Wnt signaling pathway-associated genes (PI3K, GSK-3 $\beta$, E-cadherin and $\beta$-catenin) (magnifciation, x1,000). (C) Protein expression of Wnt signaling pathway-associated transcription factors (c-myc, EphB2, FGF20 and MMP7). (D) mRNA expression of Wnt signaling pathway-associated transcription factors (c-myc, EphB2, FGF20 and MMP7). (E) Protein expression of BCR/ABL. (F) mRNA expression of BCR/ABL.

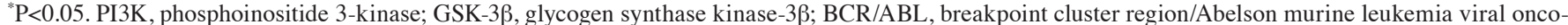
gene homolog 1; EphB2, ephrin type-B2; FGF20, fibroblast growth factor 20; MMP7, matrix metalloproteinase 7; d, days; R+SUP-B15 cells, tyrosine kinase inhibitor-resistant SUP-B15 cells; hBMSCs, human bone marrow stromal cells. 
A
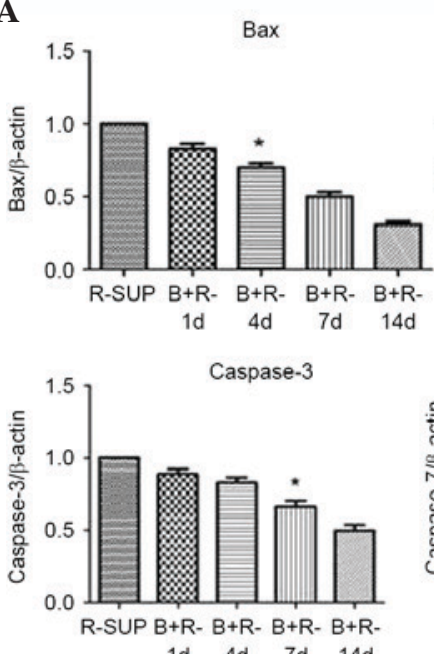

1d $4 d \quad 7 d \quad 14 d$
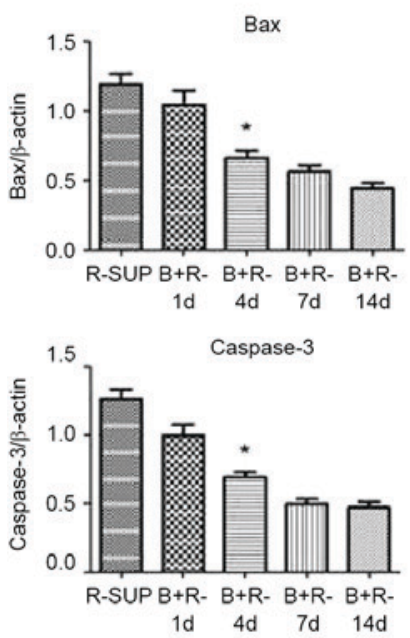

B
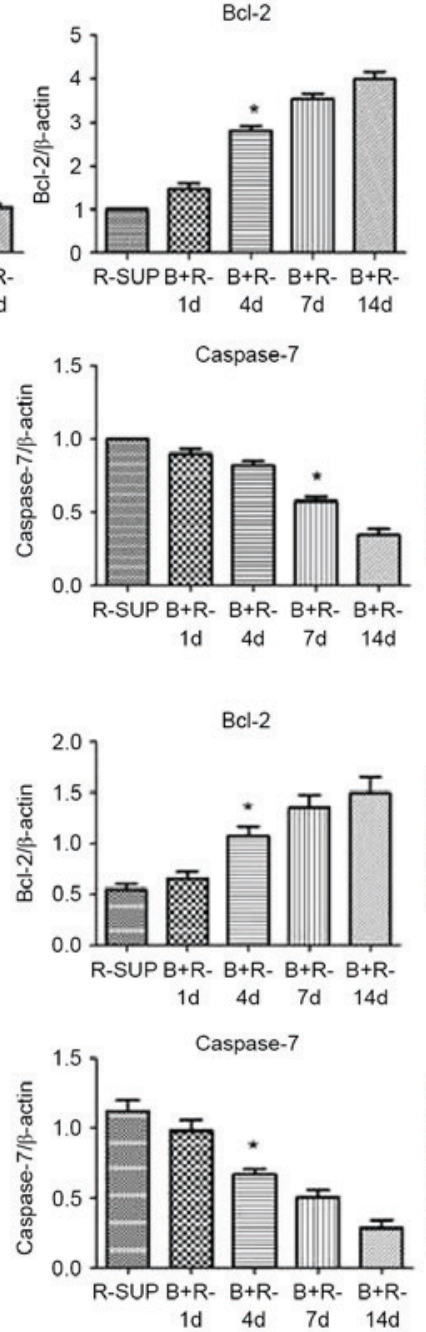
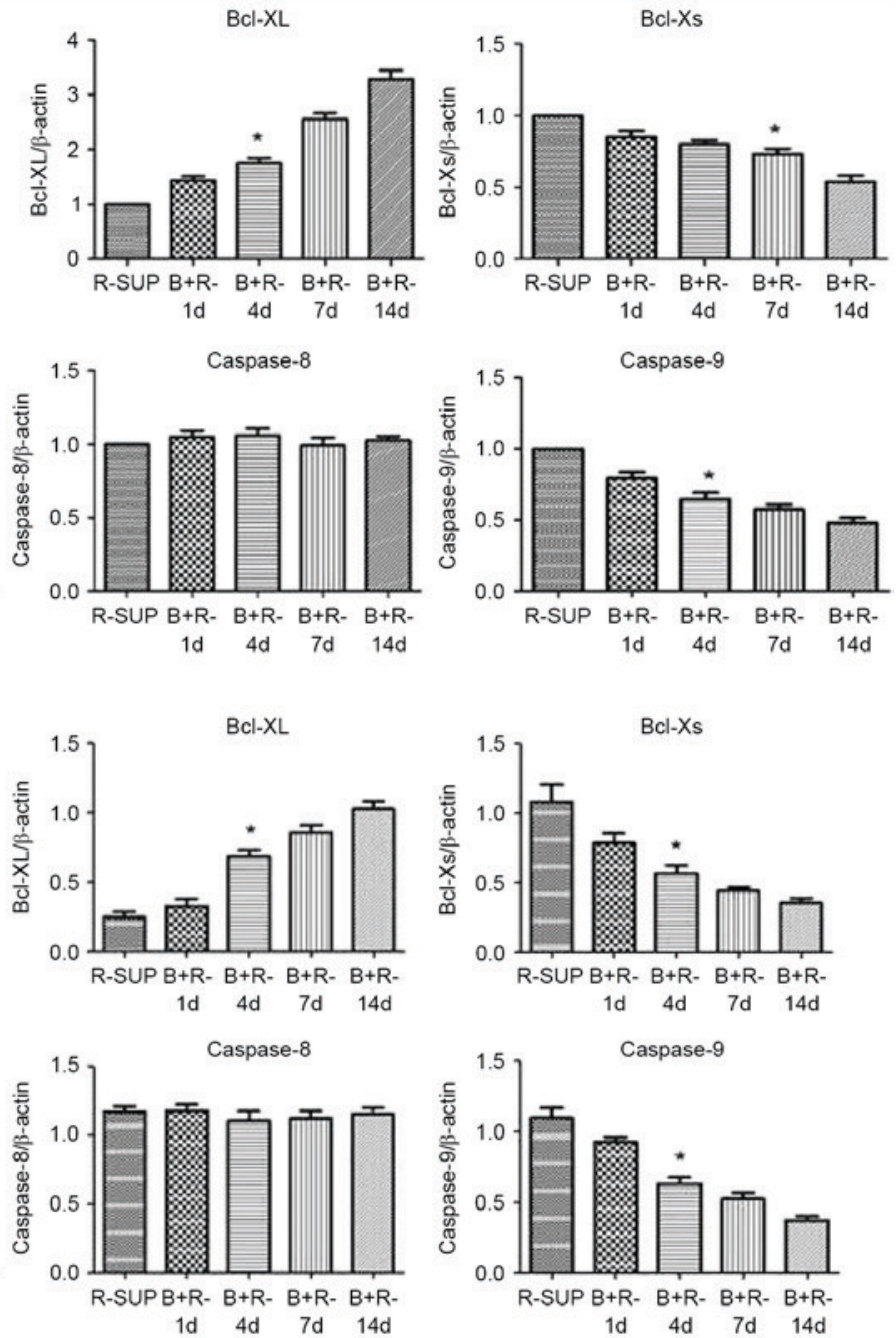

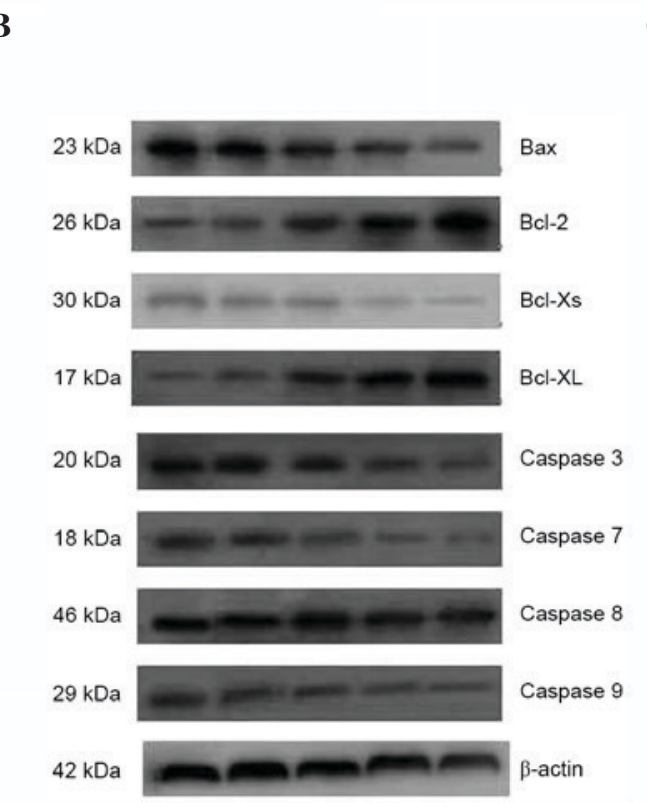

C d
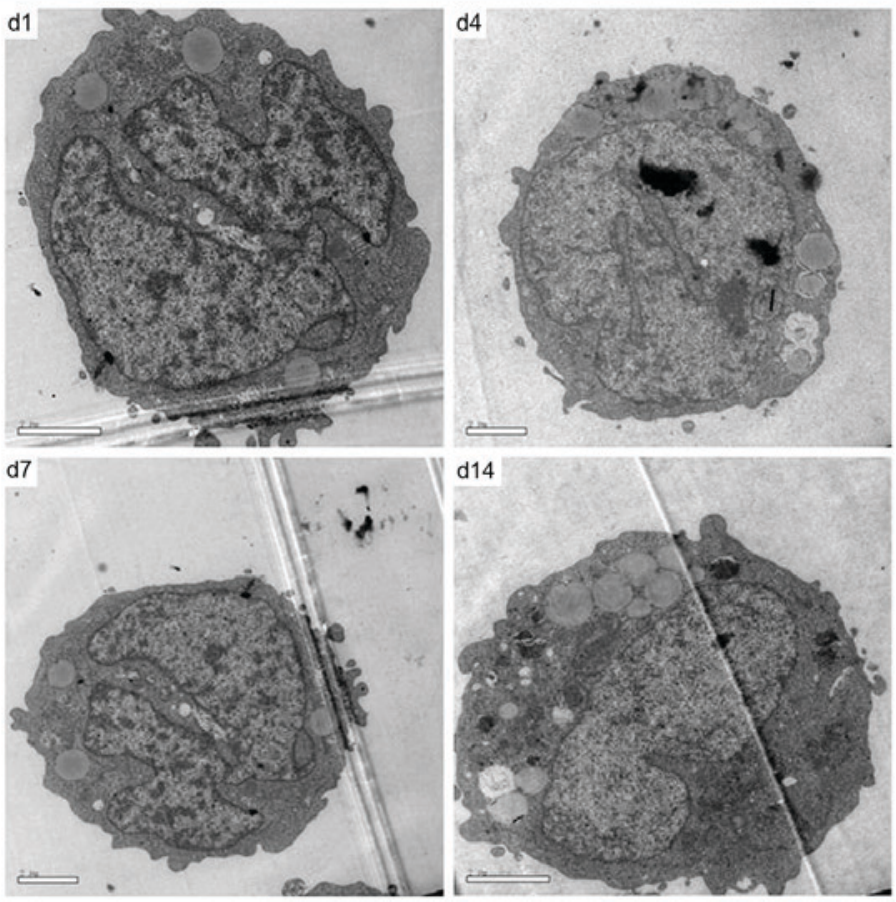

Figure 3. Apoptosis of R+SUP-B15 cells cultured with hBMSCs. hBMSCs inhibited the apoptosis of R+SUP-B15 cells and gradually increased during culture. (A) mRNA expression of anti-apoptotic genes (BCL-2 and BCL-XL), apoptotic genes (BCL-XS and Bax) and caspases 3, 7, 8 and 9. (B) Protein expression of anti-apoptotic genes (BCL-2 and BCL-XL), apoptotic genes (BCL-XS and BAX) and caspases 3, 7, 8 and 9. (C) Morphological changes of R+SUP-B15 cells. Scale bar, $2 \mu \mathrm{m}$. "P<0.05. Bcl-2, B cell lymphoma-2; Bax, Bcl-associated X protein; Bcl-XL, Bcl-extra large; d, day; R+SUP-B15 cells, tyrosine kinase inhibitor-resistant SUP-B15 cells; hBMSCs, human bone marrow stromal cells; PI, propidium iodide. 

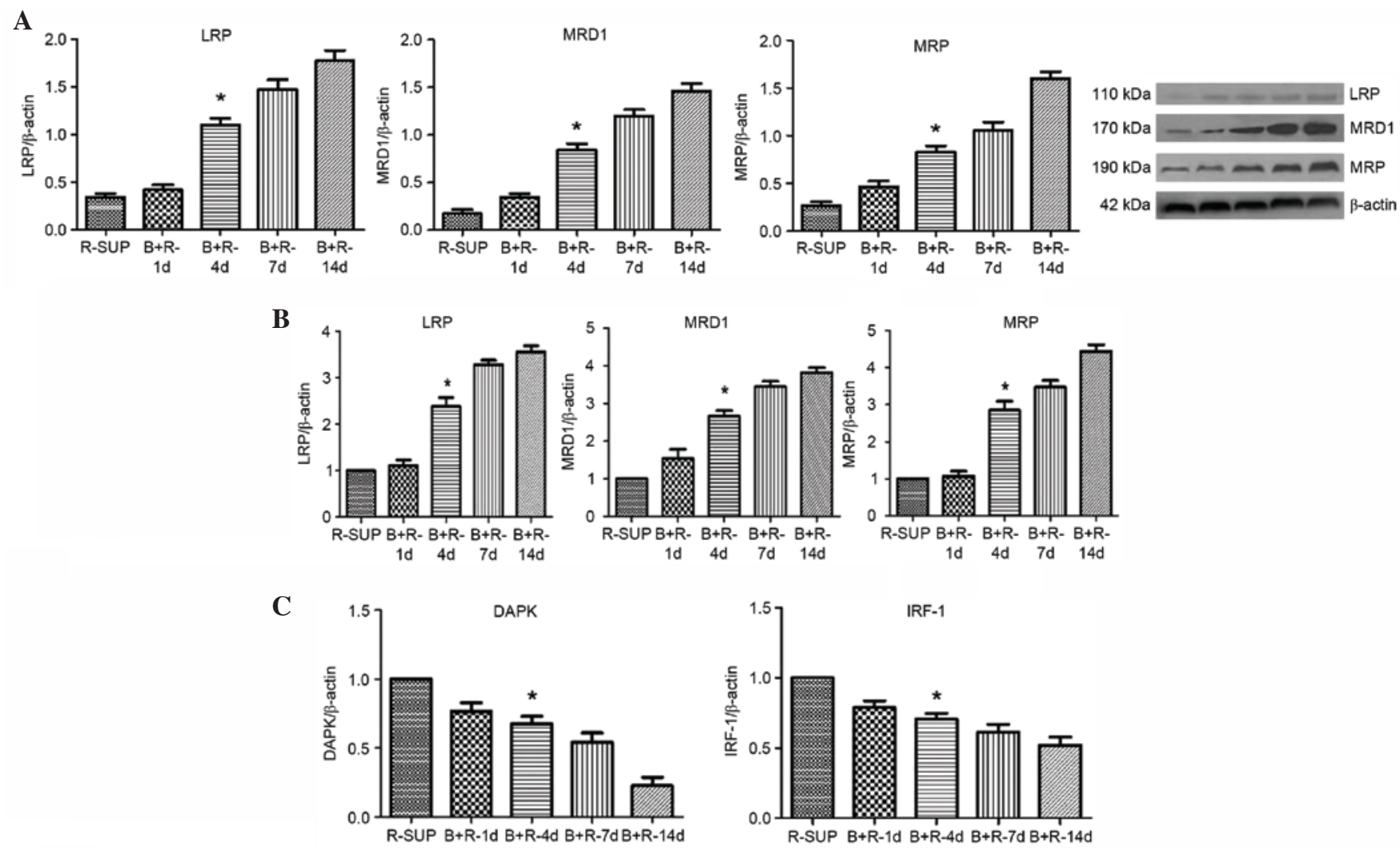

D
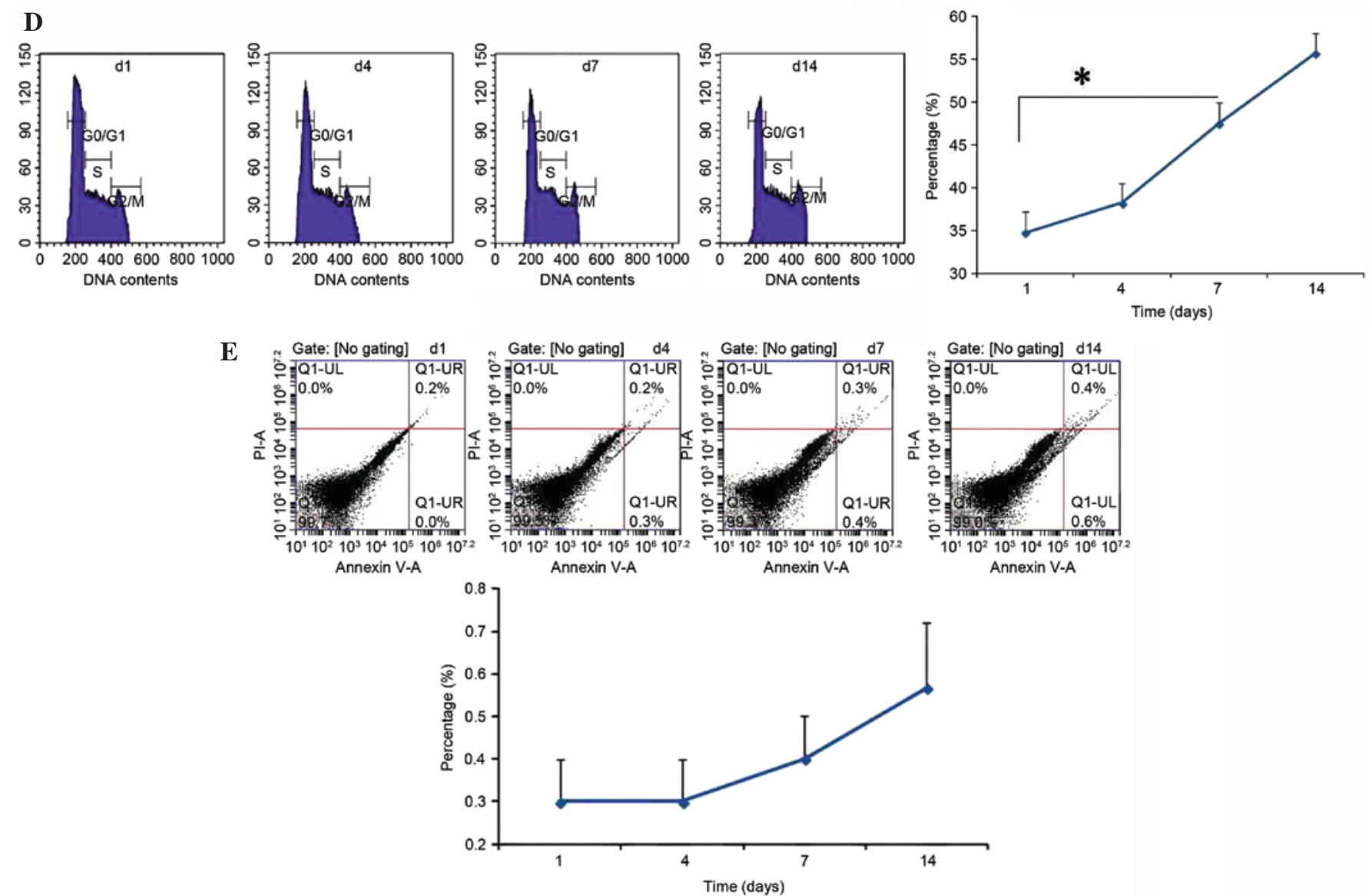

Figure 4. Drug sensitivity of R+SUP-B15 cells cultured with hBMSCs. hBMSCs inhibited anti-oncogene expression, promoted drug resistance gene expression and gradually increased during culture. No change in apoptosis combined with chemotherapy was observed. (A) Protein expression of drug resistance genes (LRP, MRP and MDR1). (B) mRNA expression of drug resistance genes (LRP, MRP and MDR1). (C) Anti-oncogene expression including DAPK and IRF-1. (D) Cell cycle after culture with hBMSCs combined with Cy. (E) Cell apoptosis after culture with hBMSCs combined with cyclophosphamide. "P<0.05. LRP, low-density lipoprotein receptor; MDR1, multi-drug resistance gene; MRP, multidrug resistance-associated protein; DAPK, death-associated protein kinase; IRF-1, interferon regulatory factor-1; d, day; PI, propidium iodide; R+SUP-B15 cells, tyrosine kinase inhibitor-resistant SUP-B15 cells; hBMSCs, human bone marrow stromal cells; PI, propidium iodide. 
profound effects on therapeutic efficacy (28-34). The present study showed that hBMSCs promoted the proliferation of TKI-resistant $\mathrm{Ph}^{+}$ALL by promoting cell cycle progression to the $\mathrm{S}+\mathrm{G} 2-\mathrm{M}$ phase and increasing the expression of cyclins A, C, D1 and E, inhibited apoptosis by upregulating anti-apoptotic genes (BCL-2 and BCL-XL) and downregulating apoptotic genes (BCL-XS, Bax and caspases 3, 7 and 9), increased expression of the BCR-ABL gene and the Wnt signaling pathway-associated genes (Wnt, GSK-3 $\beta$, $\beta$-catenin, E-cadherin and PI3K) and transcription factors (c-myc, EphB2, FGF20 and MMP7), increased expression of drug resistance genes (LRP, MRP and MDR1) and decreased the expression of anti-oncogenes (DAPK and IRF-1). In addition, no change in apoptosis was observed subsequent to combination treatment with Cy.

BMSCs provide the 'soil' for hematopoietic stem-progenitor cell homing, proliferation and differentiation. Stromal cells may play an important role in the mechanisms underlying drug resistance and apoptosis in hematological malignancies and solid tumors, depending on the tumor model (35-39). Resistance to TKI is a vital aspect in $\mathrm{Ph}^{+} \mathrm{ALL}$ due to BCR-ABL mutations (2-5). Previous studies have suggested that stromal cells may contribute to TKI-resistance in CML (21-25). The present findings showed that hBMSCs promoted the proliferation of TKI-resistant SUP-B15 cells and promoted cell cycle progression to the $\mathrm{S}+\mathrm{G} 2-\mathrm{M}$ phase. Cyclins are markers of tumor proliferation (40). The present study found that hBMSCs increased the expression of cyclins A, B, D1 and E and gradually increased with increasing culture time. Apoptosis was also observed using Hoechst 33342-PI staining and anti-apoptotic and apoptosis-associated genes were detected. The fluorescence staining with Hoechst 33342-PI was found to gradually decrease in R+SUP-B15 cells cultured with hBMSCs. hBMSCs increased the expression of BCL-2 and BCL-XL, which are proteins associated with cell proliferation. hBMSCs also increased the expression of BCL-XS, Bax, and caspases 3, 7 and 9, which are associated with cell apoptosis. R+SUP-B15 cells cultured with hBMSCs gradually grew faster, as observed by scanning electron microscopy.

Wnt signaling can regulate the $\mathrm{BCR}-\mathrm{ABL}$ gene and promote the survival and proliferation of CML stem-progenitor cells $(25,41)$. The present findings demonstrated that hBMSCs promoted the expression of the Wnt and BCR-ABL genes. Additional investigation showed that hBMSCs promoted the expression of E-cadherin, GSK-3 $\beta$, PI $3 \mathrm{~K}$ and $\beta$-catenin, which are associated with the Wnt signaling pathway. hBMSCs also promoted the expression of c-myc, EphB2, MMP7 and FGF20, which are transcription factors of the Wnt signaling pathways.

Drug resistance is associated with rapid relapse and mortality (42). The present study found that hBMSCs increased the expression of LRP, MRP and MDR1, which are associated with drug resistance. The cells also decreased the expression of anti-oncogenes DAPK and IRF-1. BMSCs from leukemia patients protect the leukemia cells from spontaneous and drug-induced apoptosis $(43,44)$. The present study showed that hBMSCs increased the proportion of R+SUP-B15 cells in the $\mathrm{S}+\mathrm{G} 2-\mathrm{M}$ phase of the cell cycle, and no change in apoptosis was observed when the chemotherapy drug was added to the medium.
Overall,the present study showed that hBMSCs can promote the growth of TKI-resistant $\mathrm{Ph}^{+}$ALL through promotion of the cell cycle, and the upregulation of cyclins, anti-apoptotic genes, BCR-ABL gene, Wnt signaling pathway-associated genes and transcription factors and drug resistance genes. Downregulation of apoptotic genes and anti-oncogenes also contributes to this. Therefore, targeting hBMSCs may be a promising approach to inhibit the growth of TKI-resistant $\mathrm{Ph}^{+}$ ALL.

\section{Acknowledgements}

The present study was funded by grants from the National Natural Science Foundation (grant no. 81170467) and Special Foundation for the ' 1130 project' of Xinqiao Hospital of the Third Military Medical University. The authors thank Professor Zhong (Department of Diagnostic Sciences \& Biomedical Sciences, Ostrow School of Dentistry, University of Southern California, Los Angeles, CA, USA) for revising the paper.

\section{References}

1. Maino E, Sancetta R, Viero P, Imbergamo S, Scattolin AM, Vespignani $M$ and Bassan R: Current and future management of Ph-BCR-ABL positive ALL. Expert Rev Anticancer Ther 14: 723-740, 2014.

2. Pfeifer H, Wassmann B, Pavlova A, Wunderle L, Oldenburg J, Binckebanck A, Lange T, Hochhaus A, Wystub S, Brück P, et al: Kinase domain mutations of BCR-ABL frequently precede imatinib-based therapy and give rise to relapse in patients with de novo Philadelphia-positive acute lymphoblastic leukemia $\left(\mathrm{Ph}^{+}\right.$ ALL). Blood 110: 727-734, 2007.

3. Soverini S, Vitale A, Poerio A, Gnani A, Colarossi S, Iacobucci I, Cimino G, Elia L, Lonetti A, Vignetti M, et al: Philadelphia-positive acute lymphoblastic leukemia patients already harbor BCR-ABL kinase domain mutations at low levels at the time of diagnosis. Haematologica 96: 552-557, 2011.

4. Pfeifer H, Lange T, Wystub S, Wassmann B, Maier J, Binckebanck A, Giagounidis A, Stelljes M, Schmalzing M, Dührsen U, et al: Prevalence and dynamics of bcr-abl kinase domain mutations during imatinib treatment differ in patients with newly diagnosed and recurrent bcr-abl positive acute lymphoblastic leukemia. Leukemia 26: 1475-1481, 2012.

5. Jones D, Thomas D, Yin CC, O'Brien S, Cortes JE, Jabbour E, Breeden M, Giles FJ, Zhao W and Kantarjian HM: Kinase domain point mutations in Philadelphia chromosome-positive acute lymphoblastic leukemia emerge after therapy with BCR-ABL kinase inhibitors. Cancer 113: 985-994, 2008.

6. Hamilton A, Helgason GV, Schemionek M, Zhang B, Myssina S, Allan EK, Nicolini FE, Müller-Tidow C, Bhatia R, Brunton VG, et al: Chronic myeloid leukemia stem cells are not dependent on Bcr-Abl kinase activity for their survival. Blood 119: 1501-1510, 2012.

7. Esposito N, Colavita I, Quintarelli C, Sica AR, Peluso AL, Luciano L, Picardi M, Del Vecchio L, Buonomo T, Hughes TP, et al: SHP-1 expression accounts for resistance to imatinib treatment in Philadelphia chromosome-positive cells derived from patients with chronic myeloid leukemia. Blood 118: 3634-3644, 2011.

8. Corbin AS, Agarwal A, Loriaux M, Cortes J, Deininger MW and Druker BJ: Human chronic myeloid leukemia stem cells are insensitive to imatinib despite inhibition of BCR-ABL activity. J Clin Invest 121: 396-409, 2011.

9. Colavita I, Esposito N, Quintarelli C, Nigro E, Pane F, Ruoppolo $\mathrm{M}$ and Salvatore F: Identification of Annexin A1 interacting proteins in chronic myeloid leukemia KCL22 cells. Proteomics 13: 2414-2418, 2013.

10. Quintarelli C, De Angelis B, Errichiello S, Caruso S, Esposito N, Colavita I, Raia M, Pagliuca S, Pugliese N, Risitano AM, et al: Selective strong synergism of Ruxolitinib and second generation tyrosine kinase inhibitor to overcome bone marrow stroma related drug resitance in chronic myelogenous leukemia. Leuk Res 38: 236-242, 2014. 
11. Bewry NN, Nair RR, Emmons MF, Boulware D, Pinilla-Ibarz J and Hazlehurst LA: Stat 3 contributes to resistance toward BCR-ABL inhibitors in a bone marrow microenvironment model of drug resistance. Mol Cancer Ther 7: 3169-3175, 2008.

12. Hazlehurst LA, Argilagos RF and Dalton WS: Betal integrin mediated adhesion increases Bim protein degradation and contributes to drug resistance in leukaemia cells. Br J Haematol 136: 269-275, 2007.

13. Nair RR, Tolentino JH, Argilagos RF, Zhang L, Pinilla-Ibarz J and Hazlehurst LA: Potentiation of Nilotinib-mediated cell death in the context of the bone marrow microenvironment requires a promiscuous JAK inhibitor in CML. Leuk Res 36: 756-763, 2012.

14. Traer E, MacKenzie R, Snead J, Agarwal A, Eiring AM, O'Hare T, Druker BJ and Deininger MW: Blockade of JAK2-mediated extrinsic survival signals restores sensitivity of CML cells to ABL inhibitors. Leukemia 26: 1140-1143, 2012.

15. Zhang B,Li M, McDonald T, Holyoake TL, Moon RT, Campana D, Shultz L and Bhatia R: Microenvironmental protection of CML stem and progenitor cells from tyrosine kinase inhibitors through $\mathrm{N}$-cadherin and Wnt- $\beta$-catenin signaling. Blood 121: 1824-1838, 2013.

16. Azizidoost S, Babashah S, Rahim F, Shahjahani M and Saki N: Bone marrow neoplastic niche in leukemia. Hematology 19: 232-238, 2014.

17. Tabe $\mathrm{Y}$ and Konopleva M: advances in understanding the leukaemia microenviroment. Br J Haematol 164: 767-778, 2014.

18. Nwajei F and Konopleva M: The bone marrow micrioenvironment as niche retreats for hematopoietic and leukemic stem cells. Adv Hematol 2013: 953982, 2013.

19. Lee HJ, Thompson JE, Wang ES and Wetzler M: Philadelphia chromosome-positive acute lymphoblastic leukemia: Current treatment and future perspectives. Cancer 117: 1583-1594, 2011.

20. Singh H, Shelat AA, Singh A, Boulos N, Williams RT and Guy RK: A screening-based approach to circumvent tumor microenvironment-driven intrinsic resistance to $\mathrm{BCR}^{-\mathrm{ABL}^{+}}$ inhibitors in $\mathrm{Ph}^{+}$acute lymphoblastic leukemia. J Biomol Screen 19: 158-167, 2014

21. Liang X, Hao L, Chen X, Zhang X, Kong P, Peng X, Gao L, Zhang $C$ and Wang Q: Efects of bone marrow stromal cells and umbilical cord blood-derived stromal cells on daunorubicin-resisant residual Jurkat cells. Transplant Proc 42: 3767-3772, 2010

22. Kang Y, Hodges A, Ong E, Roberts W, Piermarocchi C and Paternostro G: Identification of drug combinations containing imatinib for treatment of BCR-ABL ${ }^{+}$leukemias. PLoS One 9: e102221, 2014

23. Quentmeier H, Eberth S, Romani J, Zaborski M and Drexler HG: BCR-ABL1-independent PI3Kinase activation causing imatinib-resistance. J Hematol Oncol 4: 6, 2011.

24. Xing H, Yang X, Liu T, Lin J, Chen X and Gong Y: The study of resistant mechanisms and reversal in an imatinib resistant $\mathrm{Ph}^{+}$ acute lymphoblastic leukemia cell line. Leuk Res 36: 509-513, 2012.

25. Zhang $\mathrm{C}$, Chen XH, Zhang X, Gao L, Kong PY, Peng XG Liang $\mathrm{X}$, Gao L, Gong Y and Wang QY: Human umbilical cord blood-derived stromal cells, a new resource in the suppression of acute graft-versus-host disease in haploidentical stem cell transplantation in sublethally irradiated mice. J Biol Chem 286 : 13723-13732, 2011.

26. Hao L, Zhang C, Chen XH, Zou ZM, Zhang X, Kong PY, Liang X, Gao L, Peng XG, Sun AH and Wang QY: Human umbilical cord blood-derived stromal cells suppress xenogeneic immune cell response in vitro. Croat Med J 50: 351-360, 2009.

27. Tian LL, Yue W, Zhu F, Li S and Li W: Human mesenchymal stem cells play a dual role on tumor cell growth in vitro and in vivo. J Cell Physiol 226: 1860-1867, 2011.
28. McMillin DW, Negri JM and Mitsiades CS: The role of tumour-stromal interactions in modifying drug response: Challenges and opportunities. Nat Rev Drug Discov 12: 217-228, 2013.

29. Klemm F and Joyce JA: Microenvironmental regulation of therapeutic response in cancer. Trends Cell Biol 25: 198-213, 2015.

30. Teicher BA, Herman TS, Holden SA, Wang YY, Pfeffer MR, Crawford JW and Frei E III: Tumor resistance to alkylating agents conferred by mechanisms operative only in vivo. Science 247: 1457-1461, 1990.

31. Meads MB, Gatenby RA and Dalton WS: Environment-mediated drug resistance: A major contributor to minimal residual disease. Nat Rev Cancer 9: 665-674, 2009.

32. Donner A: Drug resistance: The stroma's contribution. Nat Chem Biol 8: 739, 2012.

33. Brady MT, Hilchey SP, Hyrien O, Spence SA and Bernstein SH: Mesenchymal sromal cells support the viability and differentiation of follicular lymphoma-infiltrating follicular helper T-cells. Plos One 9: e97597, 2014.

34. Ahn JO, Coh YR, Lee HW, Shin IS, Kang SK and Youn HY: Human adipose tissue-derived mesenchymal stemm cell inhibit melanoma growth in vitro and in vivo. Anticancer Res 35: $159-168,2015$.

35. Wegmeyer H, Bröske AM, Leddin M, Kuentzer K, Nisslbeck AK, Hupfeld J, Wiechmann K, Kuhlen J, von Schwerin C, Stein C, et al: Mesenchymal stromal cell characteristics vary depending on their origin. Stem Cells Dev 22: 2606-2618, 2013.

36. Strioga M, Viswanathan S, Darinskas A, Slaby O and Michalek J: Same or not the same? Comparison of adipose tissue-derived versus bone marrow-derived mesenchymal stem and stromal cells. Stem Cells Dev 21: 2724-2752, 2012.

37. Medina DJ, Goodell L, Glod J, Gélinas C, Rabson AB and Strair RK: Mesenchymal stromal cells protect mantle cell lymphoma cells from spontneous and drug-induced apoptosis through of B-cell activating factor and activation of the canonical and no-canonical nuclear factor $\mathrm{\kappa B}$ pathways. Haematologica 97: 1255-1263, 2012.

38. Bergfeld SA and DeClerk YA: Bone marrow-derived mesenchymal stem cells and the tumor microenvironment. Cancer Metastasis Rev 29: 249-261, 2010.

39. Sun B, Roh KH, Park JR, Lee SR, Park SB, Jung JW, Kang SK, Lee YS and Kang KS: Therapeutic potential of mesenchymal stromal cells in a mouse breast cancer metastasis model. Cytotherapy 11: 289-298, 2009.

40. Dutta A, Chandra R, Leiter LM and Lester S: Cyclins as markers of tumor proliferation: Immunocytochemical studies in breast cancer. Proc Natl Acad Sci USA 92: 5386-5390, 1995.

41. Fregory MA, Phange TL, Neviani P, Alvarez-Calderon F, Eide CA, O'Hare T, Zaberezhnyy V, Williams RT, Druker BJ, Perrotti D and Degregori J: Wnt-Ca2+-NFAT signaling maintains survival of $\mathrm{Ph}^{+}$leukemia cells upon inhibition of Bcr-Abl. Cancer Cell 18: 74-87, 2010.

42. Ren F, Shen J, Shi H, Hornicek FJ, Kan Q and Duan Z: Novel mechanisms and approaches to overcome multidrug resistance in the treatment of ovarian cancer. Biochim Biophys Acta 1866: 266-275, 2016.

43. Garrido SM, Appelbaum FR, Willman CL and Banker DE: Acute myeloid leukemia cells are protected from spontaneous and drug-induced apoptosis by direct contact with a human bone marrow stromal cell line (HS-5). Exp Hematol 29: 448-457, 2001.

44. Meads MB, Hazlehurst LA and Dalton WS: The bone marrow microenvironment as a tumor sanctuary and contributor to drug resistance. Clin Cancer Res 14: 2519-2526, 2008. 